\title{
Comparison of Gastrocnemius Muscle Strength between Basketballs and Non-basketball Player
}

\author{
Titing Nurhayati, ${ }^{1}$ Sharmili Mohanan, ${ }^{2}$ Marietta Shanti Prananta ${ }^{3}$ \\ ${ }^{1}$ Department of Biomedical Sciences Faculty of Medicine Universitas Padjadjaran, Indonesia, \\ ${ }^{2}$ Faculty of Medicine Universitas Padjadjaran, Indonesia, ${ }^{3}$ Department of Physical Medicine and \\ Rehabilitation Faculty of Medicine Universitas Padjadjaran/Dr. Hasan Sadikin General Hospital \\ Bandung, Indonesia
}

\section{Abstract}

Background: Basketball is one of the best aerobic-predominant exercises and the most important muscle used in this sport is the gastrocnemius muscle. This muscle plantar flexes the ankle when the knee is extended to maintain the balance and to stabilize the body during vigorous movements. Furthermore, the gluteus, quadriceps, hamstrings, and calves may get activated when running up and down the court and jump in the air when doing basketball training. This study was conducted to compare the gastrocnemius muscle strength in basketball and non-basketball players.

Methods: This analytical study was to measure the gastrocnemius muscle strength in basketball $(n=16)$ and non-basketball $(\mathrm{n}=16)$ players, using hand-held dynamometer (HHD). Gender, weight, height, Body Mass Index (BMI) and maximal gastrocnemius muscle strength were recorded and compared between groups. The study was conducted from August to October 2013 in the Faculty of Medicine, Universitas Padjadjaran.

Results: The maximal gastrocnemius muscle strength showed no significant differences both in basketball and non-basketball players for females and males with p-value 0.092 and 0.711 , respectively. Conclusions: There is no significant difference in gastrocnemius muscle strength between basketball and non-basketball players in males as well as in females. Presumably, there are other muscles that take parts to develop leg power by doing the right weight-training exercises.

Keywords: Basketball, gastrocnemius muscle, handheld dynamometer

\section{Introduction}

Physical activity is consisting of various forms of movements that require energy, for example, swimming, walking, jogging, football, basketball and many more. Basketball is one of the best aerobic exercises, ${ }^{1}$ is one of the most preferred activities by the community nowadays. ${ }^{2}$ The most important muscle used in this game is the gastrocnemius muscle which is located in the calf region. This muscle is used for plantar flexing ankle when knee is extended. This muscle helps to maintain balance and stabilize the body during vigorous movement. This muscle has an important role for a jump shot, sprinting speed as well as getting low in a defensive stance. The gastrocnemius muscle provides momentum to an individual by bending the feet while shooting. ${ }^{2}$ To reach a better gastrocnemius muscle strength, a basketball player has to train six days in a week, $1-3$ times a day and 1-2 hours per practice. ${ }^{3}$ There is no previous study about gastrocnemius muscle in a basketball player, despite this muscle is being one of the most important muscles in a basketball game. However, previous study has been conducted about the isokinetic analysis of hamstring and quadriceps femoris in Turkish second division basketball players. ${ }^{4}$ According to Kisner and Colby (1990), strength is defined as the capability of either a single or a group of muscle, either by dynamically or statically, producing tension and resulting force in one maximal effort, based on the demands placed upon them. ${ }^{5}$

Hoggan Health MicroFET 2 manual muscle testing (MMT) handheld dynamometer has been widely used in many studies, mainly because it is portable and cost-effective. This Dynamometer also precisely measures forces from different planes. It is a light-weighted

Correspondence: Titing Nurhayati, Department of Biomedical Sciences Faculty of Medicine, Universitas Padjadjaran, Jalan Raya Bandung Sumedang Km. 21 Jatinangor, Sumedang Indonesia, Email: dr.titing@gmail.com 
tool that comes in an ergonomic shape. Furthermore, this tool is accredited by the medico-legal community for its precision and validity. In MicroFET2, it has a maximum capacity of 667 Newtons (N). ${ }^{6}$ The objective of this study was to compare the gastrocnemius muscle strength between a basketball player and non-basketball player.

\section{Methods}

The study was an analytical study using crosssectional method. The subject of this study was students in the Faculty of Medicine, Universitas Padjadjaran. Thirty-two subjects were included in the study, including sixteen basketball players and sixteen non-basketball players. Each group consisted of eight males and eight females. This study was conducted in October 2013.

The inclusion criteria were students who were members of the basketball team of the Faculty of Medicine of whom trained basketball regularly for 12 months, twice per week. The non-basketball players were those who did not play basketball. The students had no medication used with known cardiac or musculoskeletal effects. The exclusion criteria were those who were having a history of lower extremity injury and history of hip, ankle and knee surgery that needed medication by the medical professions. ${ }^{7,8}$ The main goal and procedures were explained to the subjects. Upon agreeing to participate, the subjects filled the informed consent form.

The students were asked to lie on a flatsurfaced bed with their shoes of the dominant leg taken off. The examiner had to fix the strap of the dynamometer on his/her hand. Before placing the dynamometer on the feet of the students, the dynamometer was made sure to be in the "on" mode and the reading shows 0.0 Newton (N). Furthermore, the footpad of the hand-held dynamometer was placed on the sole at the prominent area right below the toes horizontally. The students had to plantarflex the ankle for 6.0 seconds (s) while the examiner resisted the movement. While the students were performing the plantar flexion, the examiner gave words of encouragement such as "Keep flexing and give your best force".

The procedure was performed three times on each subject. The first measurement was omitted because it was a practice trial for the subjects to get the feeling of pushing against the dynamometer. The test was then conducted twice on the same side with a rest period of 2 minutes. Force values in Newton (N) were recorded.

Obtained data were presented into tables and statistically analyses were conducted using the T-test (SPSS v. 15.0). The results were considered statistically significant if the $\mathrm{p}$-value was less than $0.05(\mathrm{p}<0.05)$. Analyses were performed by comparing the basketball and non-basketball players.

\section{Results}

The physical characteristic of male and female basketball players in this study was shown in Table 1. The p-value for both the male and female physical characteristics was more than 0.05 therefore both groups were homogenous and could be compared.

The maximal gastrocnemius muscle strength

Table 1 Physical Characteristics of Basketball Players and Non-basketball Players Based on Gender

\begin{tabular}{lccc}
\hline & Basketball player & Non-basketball player & \multirow{2}{*}{ P } \\
\cline { 2 - 3 } & (mean \pm SD) & (mean \pm SD) & \\
\hline Male & & & \\
Weight $(\mathrm{kg})$ & $69.50 \pm 11.40$ & $68.18 \pm 13.54$ & 0.837 \\
Height $(\mathrm{cm})$ & $169.25 \pm 6.36$ & $174.62 \pm 5.15$ & 0.085 \\
BMI & $24.14 \pm 2.59$ & $22.35 \pm 3.76$ & 0.288 \\
Female & & & \\
Weight $(\mathrm{kg})$ & $58.65 \pm 16.95$ & $57.25 \pm 6.81$ & 0.835 \\
Height $(\mathrm{cm})$ & $159.56 \pm 9.35$ & $160.87 \pm 6.37$ & 0.748 \\
BMI & $22.83 \pm 5.17$ & $22.14 \pm 2.58$ & 0.739 \\
\hline
\end{tabular}

Note: $\mathrm{SD}=$ standard deviation; BMI=body mass index 
Table 2 Maximal Gastrocnemius Muscle Strength in Male and Female Basketball Player and Non-basketball Player

\begin{tabular}{|c|c|c|c|}
\hline \multirow{2}{*}{$\begin{array}{l}\text { Maximal Gastrocnemius } \\
\text { Muscle Strength }\end{array}$} & Basketball player & Non-basketball player & \multirow{2}{*}{$\mathbf{P}$} \\
\hline & (mean $\pm S D)$ & (mean \pm SD) & \\
\hline Male & $116.47 \pm 20.74$ & $112.73 \pm 18.80$ & 0.711 \\
\hline Female & $96.93 \pm 16.18$ & $86.16 \pm 13.41$ & 0.092 \\
\hline
\end{tabular}

Note: SD=Standard Deviation

in male and female basketball players and nonbasketball players was shown in Table 2. The $\mathrm{p}$-value was more than 0.05 for both males and female, thus there was no statistical difference between both groups. However, there was a trend that basketball players had higher gastrocnemicus muscle strength although it was not significantly different.

\section{Discussion}

The result of our study shows that there is no difference between basketball players and non-basketball players for both males and females. Presumably because two muscles strengthening the exercise and both of them were made up the calf i.e. the gastronemius and soleus muscles. ${ }^{6}$

Furthermore, there are some factors that may contribute to this result, the tool itself which is the hand-held dynamometer, the patient's comfort towards the tool and the training of the players.

The reliability and validity of the handheld dynamometer are unquestionable with the evidence of previous studies. ${ }^{7}$ In order for the test to be reliable, the examiner must have a great mechanical advantage over the subject's maximal muscle strength. It is noted that when the level of movement gets tougher, the handheld dynamometer becomes less reliable. ${ }^{7}$ In this study, for the plantar flexor movement, the lever arm is short. During the pilot work to measure the plantar flexion, the hand-held dynamometer appears to be difficult though there are attempts of changing the subject's and the examiner's position. ${ }^{7}$

Apart from the limitations above, the comfort position while using the dynamometer could be considered. Though the dynamometer has a pad to lay on the body part of the subject of the study, there is disparity such as the examiner's ability. The subject may feel pain after repeated trials at the placement site because the resistance has been applied. Another issue is that strong subjects may have "give in" a little when they sense they might have weighed down the examiner. ${ }^{7}$ Therefore, to handle the dynamometer and to obtain a reliable and valid data, the examiner has to be trained beforehand. ${ }^{10}$

As for the basketball players, the limitations would be due to the lack of training to strengthen their gastrocnemius muscle. ${ }^{3}$ In this study, the basketball players practice twice per week and each practice lasts for 3 hours. Australian Institute of Sports Guidelines shows that a basketball player has to train, six times per week, 1-3 times per day and each practice should be held 1-2 hours. ${ }^{3}$ To increase the muscle strength, three phases should be taken into account. The first phase is the warm-up phase, which, in this phase, an individual can perform a few minutes of light walking. The second phase is the weight training phase and the third phase is the cool down phase which is similar to the first phase (warm-up phase). In an isotonic progressive-resistance program, an exercise frequency of an individual should be at least five days per week rather than two days per week to reach an increment of muscular strength. ${ }^{12}$

For an isometric program, a training session for 5 days per week shows a maximal isometric strength and as for an isokinetic program, which is the latest form of weight-training program, it shows a great enhancement of muscular performance. The isokinetic strength has been obtained after training for 4 days per week for 7 weeks; all these factors should be taken into account in further studies. ${ }^{12}$

The limitation of this study is possibly due to the lack of specific training among basketball player students to increase the strength of the gastrocnemius muscle. Furthermore, no information about the type of previous training that has been done by basketball and non-basketball players.

As a conclusions, there is no significant differences between the gastrocnemius muscle strength among basketball players and nonbasketball players students, as well as for the male and female in both groups. The current training program for the basketball players is insufficient to increase the maximal 
gastrocnemius muscle strength, therefore, the exercise program has to be optimized.

\section{References}

1. Bright $\mathrm{P}$. What muscles are needed in basketball?. [cited 2013 March 13]. Available from: http://www.ehow.com/ how-does_4570028_muscles-neededbasketball.html.

2. Leavitt MO. 2008 Physical activity guidelines for Americans. Washington: U.S. Department of Health and Human Services; 2008. p. 8.

3. Australian Sports Commission. Basketball. Australian Government. [cited 2013 November 15]. Available from: https:// www.sportaus.gov.au/schools/schools/ sports/basketball.

4. Findikoglu G, Alemdaroglu U, Koklu Y, Kocak FU, Erol E. Isokinetic analysis of hamstring and quadriceps muscles in Turkish second division basketball players. Ovidius University Annals, Series Physical Education and Sport/Science, Movement and Health,. 2011;11(1):5-7.

5. Jones K, Barker K. Human movement explained: physiotherapy practice explained. $1^{\text {st }}$ ed. Edinburgh: ButterworthHeinemann; 1995. p. 197.

6. Ambegaonkar, Shultz SJ, Perrin DH, Schmitz RJ, Ackerman TA, Schulz MR. Lower body stiffness and muscle activity differences between female dancers and basketball players during drop jumps. Sports Health. 2011; 3(1): 89-96.

7. Kelln BM, McKeon PO, Gontkof LM, Hertel J. Hand-held dynamometry: reliability of lower extremity muscle testing in health, physically active, young adults. J Sport Rehabil. 2008;17(2):160-70.

8. Holmes JR, Alderink GJ. Isokinetic strength characteristics of the quadriceps femoris and hamstring muscles in high school students. Phys Ther.1984;64(6):914-8.

9. Potach DH, Katsavelis D, Karst GM, Latin RW, Stergiou N. The effects of a pylometric training program on the latency time of the quadriceps femoris and gastrocnemius short-latency responses. J Sports Med Phys Fitness. 2009;49(1):35-43.

10. Andrews AW, Thomas MW, Bohannon RW. Normative values forisometric muscle force measurement obtained with hand-held dynamometers. Phys Ther. 1996;76(3):248-59.

11. Siller G. How to improve your 1-on-1 battles with muscular strength and endurance training. Pro Learning Systems. [cited 2013 November 17]. Available from: http:// prolearning.com/hockey/strength.htm.

12. Foss ML, Keteyian SJ. Fox's physiological basis for exercise and sports. $6^{\text {th }}$ ed. Michigan: William C Brown Pub/McGrawHill; 1998. p. 353-5. 